\title{
Pelatihan Teknik Pembuatan Animasi Berbasis Stop Motion di SMP N 2 Kasihan Yogyakarta
}

\author{
Tri Hastono*1, Firdiyan Syah² \\ 1,2Informatika, Fakultas Sains dan Teknologi, Universitas PGRI Yogyakarta, Indonesia \\ *e-mail: trihastono@upy.ac.id ${ }^{1}$ ryu akadent@upy.ac.id ${ }^{2}$
}

\begin{abstract}
Abstrak
Bagi seorang dosen, pengabdian pada masyarakat adalah suatu kewajiban yang dilakukan untuk memenuhi tri dharma pendidikan. Pengabdian Pada Masyarakat (PPM) yang penulis laksanakan berada di SMP N 2 Kasihan. PPM yang telah dilaksanakan berupa pelatihan untuk membuat film animasi berbasis Stop Motion. Tujuan utama dari Pengabdian Pada masyarakat (PPM) di SMP N 2 Kasihan adalah memberikan pelatihan mengenai teknik pembuatan film animasi berbasis Stop Motion. Detail dari pelatihan pada PPM yang dilakukan antara lain memberikan pengalaman dan pengetahuan tentang proses pembuatan film animasi, memeperluas wawasan dan di harapkan mampu membuat suatu karya sendiri. Adapun metode yang digunakan pada PPM Pelatihan pembuatan film animasi berbasis Stop Motion antara lain mengadakan ceramah, diskusi, dan mengadakan pelatihan/workshop. Pada PPM yang telah dilakukan menggunakan tools dalam pembuatan film animasi. Tools yang dipilih pada penelitian adalah Sony Vegas. Target yang ingin dicapai pada pengabdian pada masyarakat ini adalah meningkatkan pengetahuan dan ketrampilan siswa SMP N 2 Kasihan dalam memanfaatkan software pengolah film animasi.
\end{abstract}

Kata kunci: Animasi, SMP N 2 Kasihan, Sony Vegas, Stop Motion

\begin{abstract}
For a lecturer, community service is an obligation to fulfill the tri dharma of education. Community Service (PPM) which the author carried out was at SMP N 2 Kasihan. The PPM that has been carried out is in the form of training to make an animated film based on Stop Motion. The main objective of Community Service (PPM) at SMP N 2 Kasihan is to provide training on stop motion-based animation film-making techniques. The details of the PPM training carried out include providing experience and knowledge about the process of making animated films, broadening their horizons and being expected to be able to create their own work. The methods used in the Stop Motion-based PPM training include holding lectures, discussions, and holding training/workshops. In the PPM that has been done using tools in making animated films. The tools selected in this research are Sony Vegas. The target to be achieved in this community service is to increase the knowledge and skills of SMP N 2 Kasihan students in utilizing animated film processing software.
\end{abstract}

Keywords: Animation, SMP N 2 Kasihan, Sony Vegas, Stop Motion

\section{PENDAHULUAN}

Pada beberapa decade ini, gairah untuk memproduksi filem menggunakan teknik stop motion kembali muncul (Husniah et al., 2020)(Supriyadi, 2019). Hal tersebut terlihat dari banyaknya filem-filem yang menghiasi layar kaca kita, salah satu contohnya adalah filem Shaun the Sheep. Shaun the Sheep salah satu filem yang setiap hari tayang disalah satu stasiun televisi nasional kita. Filem-filem dengan pengerjaan teknik stop motion juga banyak yang masuk nominasi box office dengan nominal keuntungan yang fantastis, seperti filem Kubo and the Two Strings, Shaun the Sheep, Pat a Mat znovu v akci dan yang lain (Prihatiningtyas et al., 2020)(Halim et al., 2021).

Teknik Stop motion sendiri adalah Animasi Stop motion adalah suatu teknik animasi untuk membuat objek yang dimanipulasi secara fisik agar terlihat bergerak sendiri (Qamariah et al., 2017)(Rahmi \& Octarya, 2020). Stop motion sendiri pertama kali diperkenalkan oleh Stuart Blakton pada tahun 1906 (Nadya, 2012)(Husniah et al., 2020). Awal mulanya Stuart Blankton dalam membuat stop motion dengan menggambar ekspresi wajah dari sebuah tokoh kartun. Gambar tersebut dilakukan pada sebuah papan tulis yang kemudian diambil gambarnya dengan still camera. Setelah pengambilan gambar selesai, gambar pertama tersebut dihapus, Stuart 
Blankton menggambar lagi untuk eskpresi wajah selanjutnya kemudian gambar yang baru tersebut juga diambil gambarnya.

Secara umum untuk proses membuat filem stop motion sangatlah mudah dan sederhana (Wardani, 2018)(Pramono et al., 2017). Proses yang berat dari pembuatan filem atau video stop motion adalah pembuatan figure dan jalannya alur cerita filem. Dua hal tersebut memerlukan ketelitian tinggi agar memperoleh hasil yang maksimal. Namun, jika 2 hal tersebut sudah terlampaui pengerjaan video atau filem stop motion lebih ringan.

Teknik pembuatan animasi stop motion sendiri dilakukan dikomputer (Amri, 2013). Gambar dari figure yang sudah sesuai dengan story board disusun pada frame-frame dan dengan diberi waktu serta disisipi animasi maka video atau filem sudah siap dilakukan proses rendering (Pramono et al., 2017)(Purwanti \& Natanael, 2016). Hasil dari proses rendering tersebutlah video atau filem stop motion yang kita lihat dibisokop atau layar kaca kita.

Teknik animasi stop motion sendiri dapat dipelajari secara otodidak (Pramono et al., 2017). Tentunya calon animator harus mempunyai pengetahuan mengenai computer. Bagi gen alpha, hal tersebut bukan masalah serius. Hal tersebut dikarenakan oleh keseharian dari gen alpha yang tidak lepas dari teknologi (Novianti et al., 2019)(Tafonao et al., 2020). Siswa-siswa SMP N2 Kasihan merupakan bagian dari gen alpha. Jadi untuk mempelajari teknik animasi stop motion bukanlah hal yang susah.

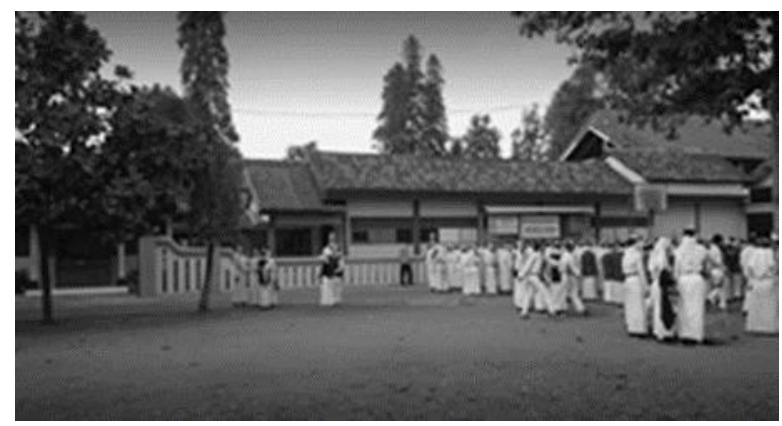

Gambar 1. SMP N 2 Kasihan

Selain gen alpha, siswa-siswa SMP N 2 Kasihan memiliki tergolong berprestasi pada diberbagai bidang, seperti: olahraga, seni suara dan seni tari. Prestasi-prestasi siswa-siswa SMP N 2 Kasihan tidak hanya pada tingkat daerah tapi sampai tingkat provinsi.

Siswa SMP N 2 Kasihan adalah wilayah Kecamatan Kasihan terbagi atas 4 desa yaitu Desa Desa Bangunjiwo, Ngestiharjo, Tirtonirmolo, Desa Tamantirto dan. Data Guru saat ini ada 23 Guru dengan jumlah PNS 20 dan Tenaga Honorer 34. Jumlah siswa saat ini mencapai 368 dengan rincian 168 putra dan 200 putri tersebar di tiga kelas pararel.

Pada saat ini, SMP N 2 Kasihan telah memiliki laboratorium komputer sendiri dengan kualitias yang bagus dan mendukung untuk editing video. Namun, sampai saat ini pemanfaatnya laboratorium hanya untuk praktikum matapelajaran yang bermuatan TI dan desain grafis. Pemanfaatan laboratorium untuk editing video belum pernah dilakukan.

Adapun analisis SWOT untuk SMP N2 Kasihan yang didapatkan ketika observasi adalah sebagai berikut:

1. Kekuatan (Strength)

a. Siswa SMP N 2 Kasihan sudah memiliki Laboratorium Komputer.

b. Siswa SMP N 2 Kasihan memiliki kemampuan seni menggambar.

2. Kelemahan (Weakness)

a. Kurangnya pengetahuan Guru dan Siswa SMP N 2 Kasihan dalam Teknik Pembuatan Animasi.

b. Kurangnya komputer yang dapat mengolah animasi.

3. Peluang (Opportunity)

a. Mendapatkan keahlian baru.

b. Meningkatkan pengetahuan Siswa SMP N 2 Kasihan. 
c. Menciptakan peluang untuk lebih berkembangnya siswa dalam hal teknik pembuatan animasi dengan software.

4. Tantangan (Threat)

a. Banyak SMP yang sudah memberikan materi animasi.

b. Perkembangan teknologi yang semakin cepat.

Berdasarkan permohonan dari guru TIK SMP N 2 Kasihan, maka pengabdi memilih tema pengabdian "Pelatihan Teknik Pembuatan Animasi Berbasis Stop Motion" bagi siswa SMP N 2 Kasihan menggunakan Sony Vegas. Adapun luaran yang diharapkan pada pengabdian adalah Meningkatkan pengetahuan pembuatan film animasi dan Meningkatkan ketrampilan siswa dalam teknik pembuatan film animasi.

\section{METODE}

Pelaksanaan pelatihan pembuatan film animasi berbasis stop motion dilaksanakan $2 \mathrm{kali}$ pertemuan 4 sesi. Pelatihan dibagi dalam 2 sesi, setiap sesi terdiri dari 2 jam pertemuan. Pertemuan pertama sesi pertama adalah mengenalkan jenis-jenis film animasi. Jenis film animasi ada 2 dimensi, 3 dimensi dan stop motion. yaitu:

Secara garis besar pelaksanaan kegiatan pengabdian ini menggunakan tiga jenis metode,

a. Ceramah

Penggunaan metode ini penyampaian materinya ditampilkan dengan media LCD, karena banyak menjelaskan materi dengan video.

b. Praktek

Cara praktik langsung menggunakan software editing sedang materi sudah dipersiapkan.

c. Tanya jawab

Tahapan metode ini peserta langsung mengutarakan kesulitan-kesulitan yang dihadapi saat praktek.

Dalam melaksanakan tiga metode ini dipilih berdasarkan tema dan isi materi, dikondisikan kemampuan peserta dalam menerima materi.

\section{HASIL DAN PEMBAHASAN}

\subsection{Deskripsi kegiatan pengabdian}

Adapun deskripsi untuk pengabdian yang dilakukan di SMP N 2 Kasihan Yogyakarta sebagai berikut:

a. Nama Kegiatan

Nama kegiatan pengabdian ini yaitu "Pelatihan Teknik Pembuatan Animasi Berbasis Stop Motion Di SMP N 2 Kasihan Yogyakarta."

b. Tempat

Kegiatan pengabdian ini dilaksanakan SMP N 2 Kasihan Yogyakarta Jalan Bibis Raya, Jetis, Tamantirto, Kasihan, Jetis, Tamantirto, Kec. Kasihan, Bantul, Daerah Istimewa Yogyakarta 55183.

c. Deskripsi

Pelatihan ini mengajarkan siswa SMP N 2 Kasihan Yogyakarta untuk membuat film animasi berbasis stop motion dengan software yang digunakan Sony Vegas. Pelatihan ini didasarkan pada permintaan dari guru-guru SMP N 2 Kasihan Yogyakarta dengan tujuan untuk memberikan pengetahuan dan kemampuan kepada siswa untuk membuat film animasi.

\subsection{Aktivitas awal pengabdian}

Terdapat beberapa aktivitas yang mendahului kegiatan pengabdian di SMP N 2 Kasihan. Aktivitas yang mendahului tersebut adalah

a. Registrasi peserta 
Pada aktivitas registrasi peserta ini perserta diwajibkan untuk mengisi daftar hadir dalam kegiatan pengabdian. Adapun waktu yang digunakan untuk registrasi peserta sekitar 15 menit.

b. Pembukaan

Pada aktivitas pembukaan ini dilakukan doa bersama untuk kelancaran acara pengabdian.

c. Sambutan-sambutan

Pada aktivitas sambuta-sambutan ini dilakukan dari dua belah pihak. Untuk sambutan dari pihak sekolah dilakukan oleh bapak Sugirman selaku kepala sekolah SMP N 2 Kasihan.

\subsection{Aktivitas inti}

Pada aktivitas ini dilakukan pelatihan pembuatan anismasi berbasis stop motion. Pada aktivitas inti dibagi menjadi 2 sesi. Sesi pertama ini berisi penyampaian materi pengenalan film animasi dan jenis-jenis dari animasi itu sendiri. Pada sesi pertama ini disampaikan juga mengenai perangkat-perangkat lunak yang biasa digunakan untuk membuat animasi yang berada dipasaran. Untuk sesi kedua dilakukan praktek dasar-dasar pembuatan animasi berbasis stop motion menggunakan software Sony Vegas.

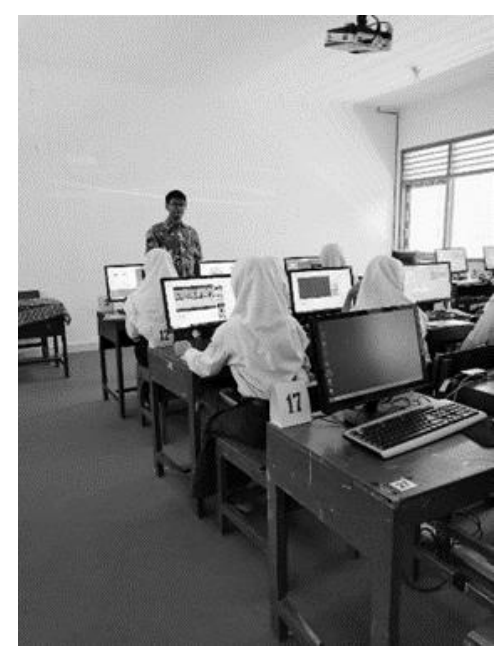

Gambar 2. Suasana kegiatan pelatihan pembuatan film animasi

Bahan-bahan praktek yang diperlukan pada pada pengabdian sudah dipersiapkan telebih dahulu, kemudian di impor ke komputer laboratorium. Bahan-bahan praktikum berupa hasil foto atau gambar digital mengenai figur atau patung. Untuk urutan prakteknya sebagai berikut:

a. Teknik Pembuatan video animasi dimulai dari pengambilan foto figure/patung dengan format JPG dan pengambilan foto untuk pembuatan animasi frame by frame (Yuliani \& Okwita, 2020; Maryanti \& Kurniawan, 2018).

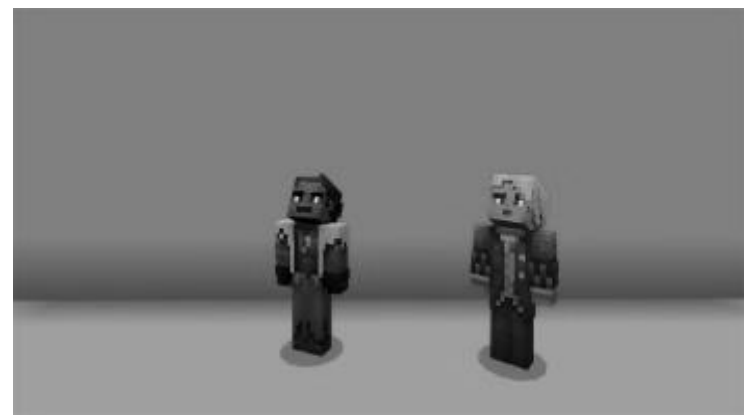

(a)

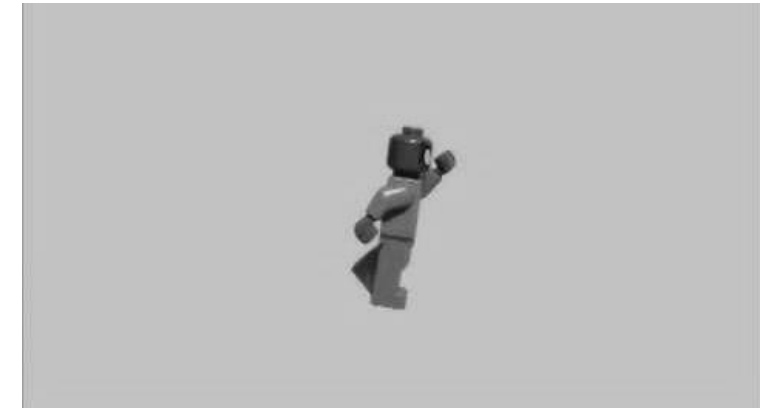

(b)

Gambar 3. Pengambilan figure untuk animasi (a), Pengambilan foto untuk pembuatan animasi frame by frame (b) 
b. Setelah dilakukan proses pengambilan foto figure, foto figure tersebut dipilih yang telah dipilih kemudian di import pada aplikasi Sony vegas dan dilakukan pengeditan pada foto tersebut.

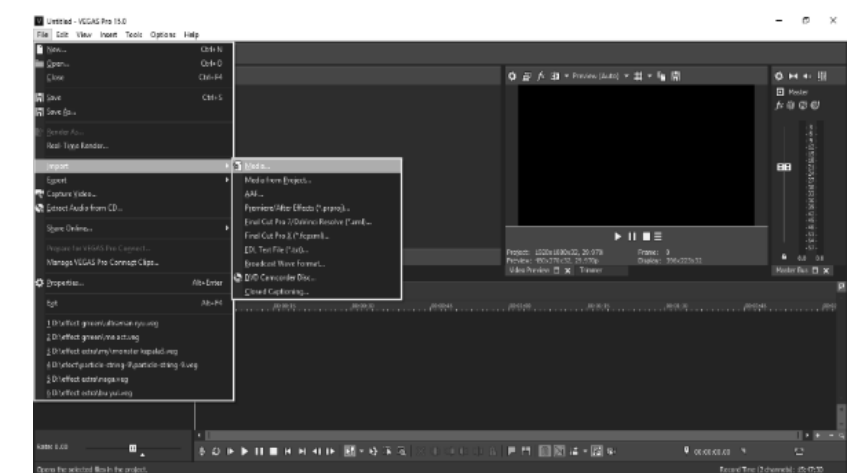

Gambar 4. Aktivitas memilih gambar yang akan di edit

c. Langkah selanjutnya adalah proses gambar siap untuk di edit artinya gambar siap di drag di fasilitas timeline. Pada timeline gambar tersebut diperhalus animasinya.

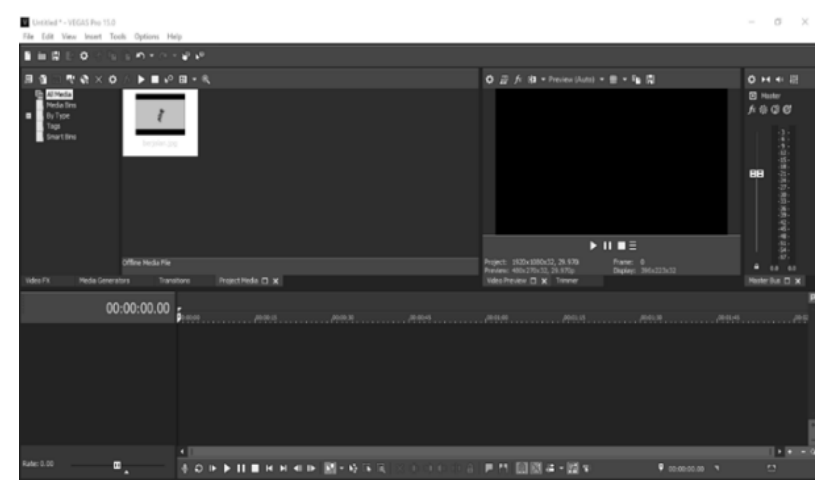

Gambar 5. Gambar proses drag ke timeline

d. Gambar diperbanyak ke arah kanan dengan cara di copy. Fungsinya adalah untuk membuat gerakan per gambar seperti orang berjalan dengan dua buah gambar yang berbeda pada posisi kaki agar hasil editing tampak real.

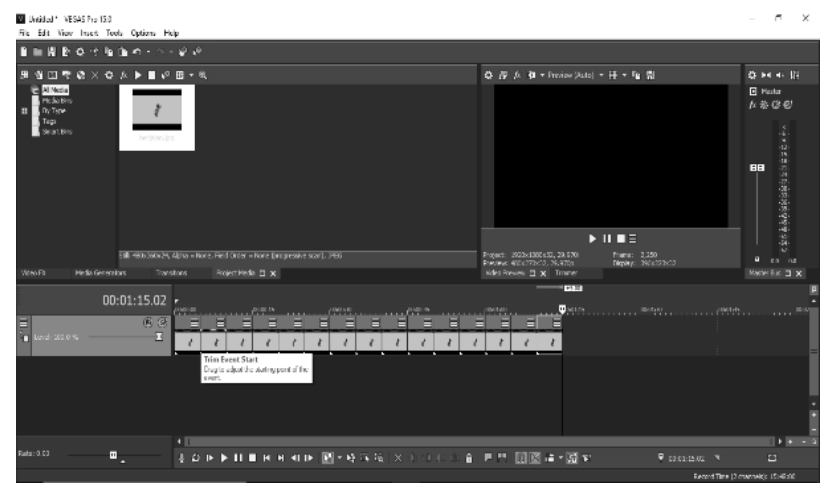

Gambar 6. Proses copy foto figur

e. Langkah selanjutnya adalah menggabungkan beberapa objek dengan teknik Chroma Key (Pradhana \& Al Fatta, 2017; Syah, 2019).

Teknik Chroma Key adalah sebuah teknik pengambilan gambar maupun video peralatannya menggunakan latar belakang kebanyakan berwarna hijau atau biru (Ardiyan et al., 2020; Syah, 2019). Green Screen adalah sebuah pengambilan gambar ataupun video dengan latar 
belakang menggunakan warna hijau ataupun biru. Teknik Chroma Key membutuhkan Blue Screen atau Green Screen (Astuti et al., 2016).

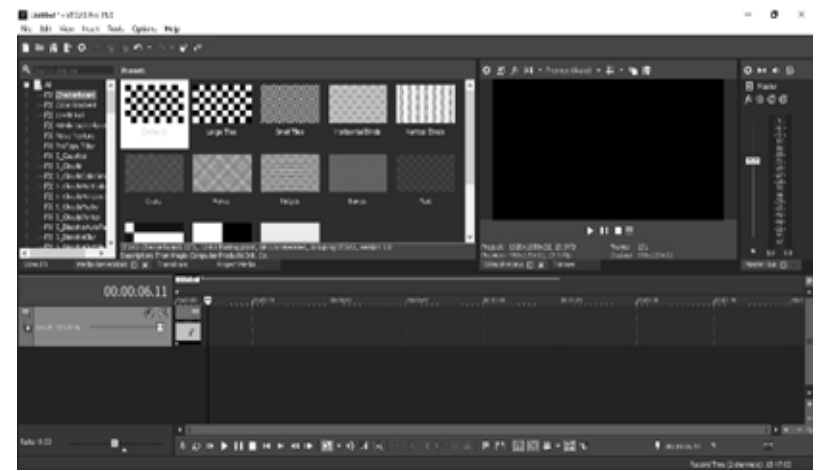

Gambar 7. Penggunaan teknik Chroma Key

f. Dari timeline diarahkan ke gambar agar terlihat pada layer hasil editing di sebelah kanan. Area ini menjadi area untuk proses editing karena editing di timeline menjadi sumber keseluruhan yang hasilnya dilihat pada layer utama.

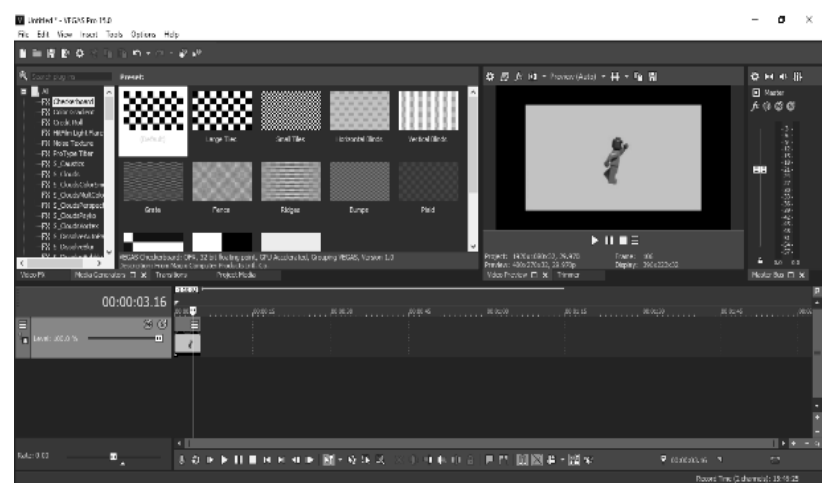

Gambar 8. Proses penggunakan Chrome key pada timeline

g. Langkah selanjutnya meletakkan tool pen ke warna hijau ke dalam gambar pada layar menu utama sampai proses chrome key selesai

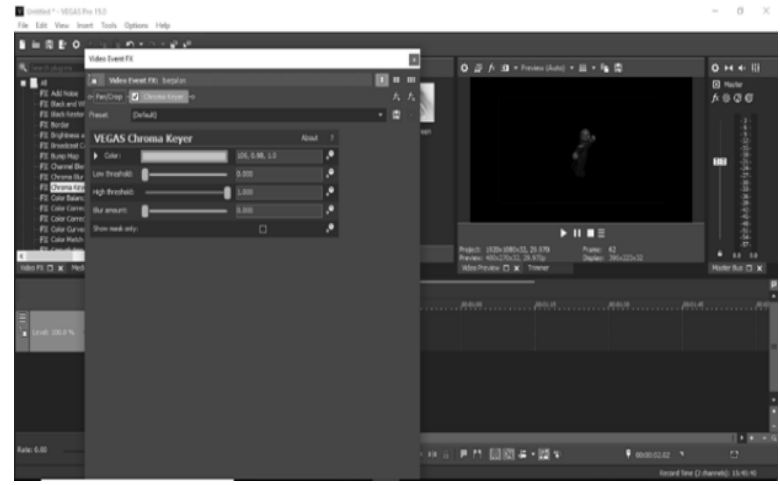

Gambar 9. Penggunaan tool pen

h. Proses akhir adalah proses rendering

Proses Rendering adalah satu proses membangun gambar model oleh computer (Pramono et al., 2017) (Hadi, 2021). Berkas adegan tersebut mengolah objek-objek dalam atau struktur, bisa berupa geometri sudut pandang, pencahayaan, tekstur, dan informasi sebagai bentuk deskripsi dari adegan virtual. Data ini di dalam dokumen adegan lalu melewati fasilitas rendering diproses menjadi hasil sebuah gambar digital proses. 


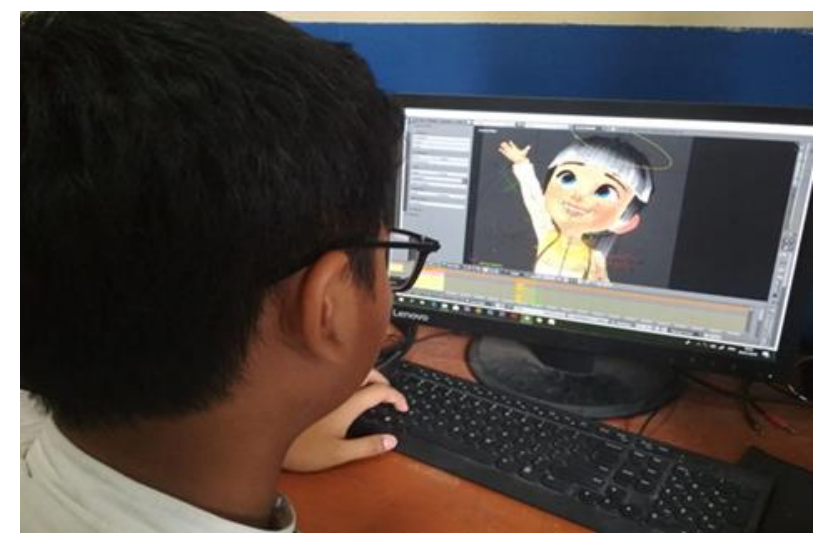

Gambar 10. Proses rendering dari salah satu siswa SMP N 2 Kasihan

Proses rendering yang dilakukan oleh siswa SMP N 2 Kasihan sendiri tidak semua berhasil. Hal tersebut dikarenakan keterbatasan waktu pengabdian dan waktu yang diperlukan rendering video yang cukup memakan waktu.

Secara keseluruhan siswa sudah mengetahui bagaimana pembuatan teknik animasi stop motion menggunakan sony vegas. Dan pengabdian yang telah dilaksanakan memberikan sumbangsih berupa pengetahuan bagi siswa SMP N2 Kasihan.

\section{KESIMPULAN}

Kegiatan pengabdian pada masyarakat yang telah dilaksanakan di SMP N2 Kasihan sudah berjalan dengan lancar. Pengabdian tersebut mendapatkan respon dari pihak sekolah dan siswa siswa, karna pelatihan untuk pembuatan animasi menggunakan stop motion baru pertama kali bagi siswa SMP N2 Kasihan. Pelatihan pembuatan animasi menggunakan Stop Motion menambah ketrampilan siswa SMP N2 Kasihan.

\section{DAFTAR PUSTAKA}

Amri, T. S. (2013). 2013 IMPLEMENTASI TEKNIK STOP MOTION PADA PEMBUATAN VIDEO KLIP CHOICE BAND SEBAGAI MEDIA PROMOSI KREATIF.

Halim, A. E., Russel, J., \& Nathanael, K. (2021). Analysis on Laika's Puppets in Kubo and the Two Strings: A Stop-motion Animated Feature. IMOVICCON Conference Proceeding, 2(1), 46-53. https://doi.org/10.37312/imoviccon.v2i1.35

Husniah, L., Prihatiningtyas, S., \& Putra, I. A. (2020). Pengembangan media pembelajaran video stop motion materi fluida statis. Jurnal Riset Dan Kajian Pendidikan Fisika, 7(1), 15. https://doi.org/10.12928/jrkpf.v7i1.14625

Nadya. (2012). Kajian Perkembangan Animasi Stopmotion Di Indonesia. Jurnal RUPARUPA, 1(2), 77-80. http://www.sfi.se

Novianti, R., Hukmi, \& Maria, I. (2019). GENERASI ALPHA - TUMBUH DENGAN GADGET DALAM GENGGAMAN. JURNAL EDUCHILD, 8(2), 65-70.

Pramono, W., Suyanto, M., \& Sofyan, A. F. (2017). Perbandingan Metode Frame By Frame Dan Expression Dalam Pembuatan Animasi Dua Dimensi. Seminar Nasional Sains Dan Teknologi 2017, November, 1-2.

Prihatiningtyas, I., Prasetyo, S. A., \& Widyaningrum, A. (2020). Daya Tangkap Siswa SD dan Orangtua Terhadap Film Animasi Kubo and The Two Strings. Jurnal Ilmiah Pendidikan Profesi Guru, 3(2), 394. https://doi.org/10.23887/jippg.v3i2.28999

Purwanti, R., \& Natanael, R. (2016). Video Animasi Stop Motion Sebagai Media Pembelajaran Pada Kampanye Pengenalan Tertib Berlalu Lintas Bagi Remaja Pengendara Sepeda Motor. Widyakala, 3(1), 1-8. 
Qamariah, W., Daningsih, E., \& Yokhebed. (2017). Kelayakan animasi stop motion pembuatan cake pepaya submateri peran tumbuhan di bidang ekonomi. Jurnal Pendidikan Informatika Dan Sains, 6(2), 267-279. https://journal.ikippgriptk.ac.id/index.php/saintek/article/view/682

Rahmi, A. D., \& Octarya, Z. (2020). Desain Dan Uji Coba Media Pembelajaran Video Animasi Stop Motion Berbasis Saintifik Pada Materi Ikatan Kimia. Jurnal Eksakta Pendidikan (Jep), 4(2), 122. https://doi.org/10.24036/jep/vol4-iss2/509

Supriyadi. (2019). Perancangan Animasi Stopmotion Pangeran Diponegoro Berbasis

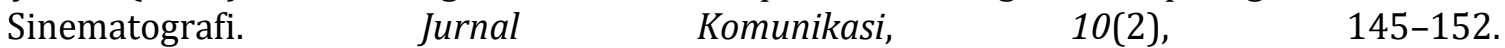
https://doi.org/10.31294/jkom.v10i2.6181

Tafonao, T., Saputra, S., \& Suryaningwidi, R. (2020). Learning Media and Technology : Generation $\mathrm{Z}$ and Alpha. Indonesian Journal of Instructional Media and Model, 2(2), 89-100.

Wardani, S. M. (2018). PENGEMBANGAN MEDIA PEMBELAJARAN VIDEO STOP MOTION PADA PELAJARAN DASAR-DASAR DESAIN KRIYA KELAS X SEKOLAH MENENGAH KEJURUAN (Issue April). 